\title{
Étude bactériologique de l'ultrafiltration du lait et du stockage au froid du rétentat
}

\author{
par \\ Louise Veillet-Poncet, (A.) Tayfour, (J. B.) Millière*
}

Depuis que Maubois, Mocquot et Vassal [51] ont mis au point, en 1969, l'utilisation de lait concentré par ultrafiltration, "procédé M.M.V. ", en fabrication fromagère, l'application de cette technique, dans l'industrie laitière, n'a cessé de progresser.

Les seules études d'ordre bactériologique consacrées à ce procédé rapportent les taux de multiplication cellulaire au cours de l'ultrafiltration $[39,40,41,49,62,66,67,68,70]$, mais aucune ne traite de l'évolution de la flore microbienne au niveau du rétentat stocké à différentes températures.

Nous nous proposons, dans ce travail, d'analyser le développement des flores bactériennes mésophile, psychrotrophe, psychrotrophe caséolytique et coliforme et de déterminer les espèces dominantes au cours de l'ultrafiltration et pendant le stockage du lait et du rétentat à des températures de 4,7 et $12^{\circ} \mathrm{C}$ jusqu'à $96 \mathrm{~h}$.

\section{MATERIEL ET METHODES}

\subsection{Origine du lait}

Le lait provient de la ferme expérimentale de l'E.N.S.A.I.A. Pour chaque expérience, 601 de lait cru entier sont prélevés de la traite du matin, d'un troupeau de 80 vaches laitières. Acheminé aussitôt au Centre Laitier, le lait est écrémé à la température de $35^{\circ} \mathrm{C}$, dans une centrifugeuse "Alfa-Laval ».

\subsection{Ultrafiltration du lait}

Le module d'ultrafiltration Pléiade, type UFP8 "Rhône-Poulenc " est équipé de douze membranes synthétiques IRIS 3038, dont le seuil

\footnotetext{
* Laboratoire de Microbiologie Alimentaire, I.N.P.L.-E.N.S.A.I.A., Nancy.
} 
de coupure est proche de 20000 ; elles représentent une surface d'ultrafiltration de $1 \mathrm{~m}^{2}$. Le module est relié à une cuve thermostatée de 1001 .

L'ultrafiltration de $50 \mathrm{~kg}$ de lait écrémé est conduite à la température de $35^{\circ} \mathrm{C}$, jusqu'à obtention d'une concentration de quatre fois en poids, par élimination de $37,5 \mathrm{~kg}$ d'ultrafiltrat. Le rétentat ainsi obtenu a un E.S.T. de 19 p. 100 et une teneur en lactose de $50 \mathrm{~g} / \mathrm{l}$.

\subsection{Conditions de stockage des échantillons}

Les échantillons de lait écrémé, incubés à $35^{\circ} \mathrm{C}$ pendant les 65 min que dure l'opération d'ultrafiltration, et les échantillons de rétentat, répartis également, à raison de $150 \mathrm{ml}$, dans des flacons stériles de $250 \mathrm{ml}$, sont stockés aux températures de 4,7 et $12^{\circ} \mathrm{C}$ pendant $4 \mathrm{j}$.

Le choix de ces températures découle de plusieurs observations : $4^{\circ} \mathrm{C}$ est la température préconisée pour le stockage du lait en tank à la ferme; la température de $7^{\circ} \mathrm{C}$ favorise la croissance des espèces psychrotrophes, sans permettre le développement des espèces mésophiles et est retenue, par la F.I.L., pour le dénombrement des bactéries psychrotrophes et $12^{\circ} \mathrm{C}$ correspond, dans certains cas, aux conditions de stockage à l'usine et à la température de maturation des laits.

Le début du stockage intervient 2 h 15 min après la fin de la traite.

\subsection{Dénombrements des flores aérobies mésophile, psychrotrophe, psychrotrophe caséolytique et de la flore coliforme}

Les numérations des diverses flores bactériennes des échantillons de lait et de rétentat, avant et pendant toute la durée du stockage, sont réalisées toutes les $24 \mathrm{~h}$, selon le protocole suivant :

- pour les flores aérobies mésophile et psychrotrophe, sur milieu Tryptone-Agar de la F.I.L., après respectivement $72 \mathrm{~h}$ d'incubation à $30^{\circ} \mathrm{C}$ et $10 \mathrm{j}$ à $7^{\circ} \mathrm{C}$;

- pour la flore psychrotrophe caséolytique, sur milieu gélosé au lait, après $10 \mathrm{j}$ d'incubation à $7^{\circ} \mathrm{C}$;

- pour la flore coliforme, soit sur milieu au désoxycholate lactose agar, soit sur milieu lactosé bilié au vert brillant (V.B.). Trois tubes de V.B., pour chaque dilution, sont ensemencés et la détermination du N.P.P. est obtenue à l'aide de la table de Mac Crady.

\subsection{Isolement et identification des espèces dominantes des flores psychrotrophes caséolytiques ou non et coliformes}

L'identification de ces espèces bactériennes est réalisée d'une part à partir du lait cru, avant ultrafiltration, et d'autre part à partir des rétentats stockés aux températures préalablement définies. 


\subsubsection{Isolement des clones}

Seules sont retenues, pour le repiquage des colonies, les plaques de gélose comportant entre dix et cent colonies. Le nombre de colonies prélevées est égal à la racine carrée de la numération bactérienne et toutes sont repiquées en bouillon nutritif (B.N.) et incubées à $30^{\circ} \mathrm{C}$ pendant 24 à $48 \mathrm{~h}$.

En ce qui concerne la flore coliforme, la confirmation de la pureté de la souche est obtenue en réalisant des isolements sur milieu gélosé lactosé au pourpre de bromocrésol, incubé à $30^{\circ} \mathrm{C}$ pendant $48 \mathrm{~h}$.

Pour les flores psychrotrophe et psychrotrophe caséolytique, ces isolements sont effectués respectivement sur Tryptone-Agar et sur gélose au lait, incubées pendant $48 \mathrm{~h}$ à $30^{\circ} \mathrm{C}$. Sur ce dernier milieu, la vérification de l'activité protéolytique de la souche est obtenue par la persistance du halo de protéolyse, après inondation de la surface de la gélose avec une solution d'HCl dilué [36].

Chaque type de colonie est ensuite repiqué sur gélose nutritive inclinée, incubée à $30^{\circ} \mathrm{C}$ pendant $24 \mathrm{~h}$, puis après développement bactérien, le clone est conservé à $4^{\circ} \mathrm{C}$, jusqu'à son identification.

\subsubsection{Identification des clones}

L'identification des clones est conduite d'après les caractères morphologiques, physiologiques et biochimiques retenus par Millière et Veillet-Poncet $[56,57]$ et en ce qui concerne les bactéries à pigment caroténoïde jaune ou de couleur orange, nous nous référons à la clef d'identification proposée par Gilardi en 1975 [26].

\subsection{Mesure de l'acidité titrable et du pH}

La mesure de l'acidité titrable, exprimée en degrés Dornic, est effectuée selon la méthode officielle d'analyse des laits; l'évaluation du $\mathrm{pH}$ est obtenue sur un $\mathrm{pH}$-mètre de marque Tacussel.

\section{RESULTATS ET DISCUSSION}

\subsection{Qualité bactériologique des laits d'origine et des rétentats obtenus}

Les six prélèvements de lait cru entier analysés dans notre étude sont choisis en fonction de leurs niveaux de population en flore aérobie mésophile (F.A.M.) sensiblement identiques et compris entre $1,1.10^{4}$ et $2.10^{4}$ bactéries par ml. Ces échantillons montrent cependant une très grande hétérogénéité dans leur contamination, en ce qui concerne les proportions relatives des flores psychrotrophe, psychrotrophe caséolytique et coliforme. 


\section{TABLEAU 1}

Moyennes des dénombrements bactériens (exprimés par ml) et des proportions des différentes flores par rapport à la F.A.M.

\begin{tabular}{|c|c|c|c|c|c|}
\hline \multicolumn{2}{|l|}{ Echantillons } & Mésophile & $\begin{array}{l}\text { Psychro- } \\
\text { trophe }\end{array}$ & $\begin{array}{l}\text { Psychro- } \\
\text { trophe } \\
\text { caséolytique }\end{array}$ & Coliforme \\
\hline \multicolumn{2}{|c|}{ Lait } & $1,4.10^{4}$ & $2,8.10^{3}$ & $2,4.10^{2}$ & 25 \\
\hline \multicolumn{2}{|c|}{ Rétentat } & $1.10^{5}$ & $2,7.10^{4}$ & $2,3.10^{3}$ & $1,10^{3}$ \\
\hline p. 100 flores & Lait & - & 20 & 1,7 & 0,2 \\
\hline à la F.A.M. & Rétentat & - & 27 & 2,3 & 1 \\
\hline
\end{tabular}

Seules sont mentionnées dans notre travail les moyennes arithmétiques des dénombrements bactériens et les principales espèces identifiées.

En se référant aux travaux de Thomas [78] relatifs à la qualité bactériologique du lait $\mathrm{cru}$, nous pouvons considérer que les conditions d'hygiène à la ferme sont satisfaisantes, puisque pour nos six échantillons, la F.A.M. est inférieure à $5.10^{4}$ bactéries $/ \mathrm{ml}$. La contamination en bactéries psychrotrophes, toujours nettement inférieure au barème préconisé $\left(\mathrm{N}<1.10^{4}\right.$ bactéries $\left./ \mathrm{ml}\right)$ permet d'assurer une bonne conservation du lait pendant $48 \mathrm{~h}$ à $4^{\circ} \mathrm{C}$ [83]. Cependant, le nombre important, bien qu'acceptable, des bactéries coliformes (de 10 à 95 bactéries par $\mathrm{ml}$ ) pourrait être réduit par une hygiène encore plus rigoureuse.

Pour les rétentats, nous ne pouvons conclure sur la base de ces travaux qui ne se réfèrent qu'à la qualité bactériologique des laits réfrigérés, car l'augmentation du nombre de bactéries dépend à la fois du taux de concentration du rétentat et d'une éventuelle prolifération bactérienne pendant l'ultrafiltration.

Après confirmation que les bactéries sont retenues par la membrane d'ultrafiltration et donc concentrées dans le rétentat, nous déterminons selon Maubois et Mocquot [49], le facteur de multiplication bactérienne $\mathrm{F}$. Les moyennes obtenues pour $\mathrm{F}$ sont respectivement de 1,67 $\pm 0,31$ pour la F.A.M., de 1,91 $\pm 0,66$ pour la flore 
psychrotrophe, de 1,98 $\pm 0,68$ pour la flore psychrotrophe caséolytique et de $11 \pm 1,85$ pour la flore coliforme. Ces résultats indiquent que la population bactérienne des trois premières flores, en faisant abstraction du taux de concentration du rétentat, a presque doublé pendant l'ultrafiltration réalisée à $35^{\circ} \mathrm{C}$ pendant $65 \mathrm{~min}$. Cependant, nous considérons que seule l'augmentation notable du nombre de bactéries coliformes, observation qui concorde avec celle de Maubois et Mocquot [49], Kiviniemi et Seuranen [40], est significative. En effet, la proportion des bactéries coliformes dans la F.A.M. est multipliée par un facteur 6, alors que les pourcentages des flores psychrotrophes restent sensiblement identiques (facteur de multiplication égal à 1,35 ).

L'identification des espèces bactériennes, constituant les flores aérobies psychrotrophes, élaborant ou non des protéases, et de la flore coliforme, traduit une grande hétérogénéité dans la composition des flores des six échantillons de lait analysés, bien que tous proviennent d'une même étable et soient prélevés au printemps.

Cependant, nous isolons principalement toujours les mêmes espèces et nous pouvons admettre que pour l'ensemble de nos échantillons, la flore psychrotrophe est constituée, par ordre décroissant, de P. fluorescens, de Flavobacterium $\mathrm{II}_{\mathrm{n}}$ et d'Acinetobacter. Ces deux premières espèces constituent également la flore psychrotrophe caséolytique dominante et leur aptitude à élaborer des protéases très actives est confirmée dans de nombreux travaux.

La flore coliforme qui représente entre 0,03 p. 100 et 0,87 p. 100 de la F.A.M., est constituée en majorité d'E. coli et d'Enterobacter cloacae et en plus faible proportion de Citrobacter intermedium et de Citrobacter freundii.

Dans du lait cru, Hellmann [30] identifie également principalement $E$. coli, tandis que Arca et Maida [3] rapportent que $2 / 3$ des souches coliformes examinées appartiennent au genre Enterobacter avec une prédominance de l'espèce E. cloacae.

Dans le rétentat, en raison d'une concentration bactérienne plus importante, nous isolons un plus grand nombre d'espèces qu'à partir du lait cru d'origine. Cependant, nous n'observons pas de modifications importantes dans la composition des flores étudiées, car nous identifions, à côté des espèces dominantes, en très faibles proportions, dans la flore aérobie psychrotrophe, Pseudomonas putida, Flavobacterium $I I_{E}$, Xanthomonas, $A$. hydrophila et $K$. pneumoniae, et dans la flore psychrotrophe caséolytique, des espèces à pigments caroténoïdes jaunes ou de couleur orange, telles que Xanthomonas et VE.2. La composition de la flore coliforme, qui représente après ultrafiltration entre 0,3 et 2,4 p. 100 de la F.A.M., reste également sensiblement identique, et à côté des espèces dominantes déjà isolées à partir du lait cru, nous identifions quelques Enterobacter hafniae et $K$. pneumoniae. 


\subsection{Evolution des différentes flores au cours du stockage à 4,7 et $12^{\circ} \mathrm{C}$}

\subsubsection{Flore aérobie mésophile}

TABLEAU 2

Dénombrement et taux de multiplication de la F.A.M. dans le lait et le rétentat crus au cours du stockage

\begin{tabular}{|c|c|c|c|c|c|}
\hline \multicolumn{2}{|c|}{ Durées de stockage } & \multirow{2}{*}{$24 \mathrm{~h}$} & \multirow{2}{*}{$48 \mathrm{~h}$} & \multirow{2}{*}{$72 \mathrm{~h}$} & \multirow{2}{*}{$96 \mathrm{~h}$} \\
\hline Température & Substrat & & & & \\
\hline $4^{\circ} \mathrm{C}$ & $\begin{array}{l}\text { lait } \\
\text { rétentat }\end{array}$ & $\begin{array}{c}1,2.10^{4} \\
(0,86) \\
1.105 \\
(1)\end{array}$ & $\begin{array}{c}1,1.10^{4} \\
(0,79) \\
1,4.10^{5} \\
(1,4)\end{array}$ & $\begin{array}{c}1,5.10^{4} \\
(1,1) \\
6.10^{5} \\
(6)\end{array}$ & $\begin{array}{c}1,3.10^{5} \\
(9,3) \\
4,4.10^{6} \\
(44)\end{array}$ \\
\hline $7^{\circ} \mathrm{C}$ & $\begin{array}{l}\text { lait } \\
\text { rétentat }\end{array}$ & $\begin{array}{c}9.10^{3} \\
(0,64) \\
4,4.10^{4} \\
(0,44)\end{array}$ & $\begin{array}{c}2,95.10^{5} \\
(21,1) \\
3.10^{5} \\
(3)\end{array}$ & $\begin{array}{c}5,8.10^{6} \\
(414,3) \\
6,6.10^{6} \\
(66)\end{array}$ & $\begin{array}{c}2,3.10^{7} \\
(1642,9) \\
3,2.10^{7} \\
(320)\end{array}$ \\
\hline $12^{\circ} \mathrm{C}$ & $\begin{array}{l}\text { lait } \\
\text { rétentat }\end{array}$ & $\begin{array}{c}4.10^{5} \\
(28,6) \\
6,5.10^{5} \\
(6,5)\end{array}$ & $\begin{array}{c}1,72.10^{7} \\
(1228,6) \\
3,5.10^{7} \\
(350)\end{array}$ & $\begin{array}{c}1,24.10^{8} \\
(8857,1) \\
4,1.10^{8} \\
(4100)\end{array}$ & $\begin{array}{c}3,7.10^{8} \\
(26428) \\
10^{9} \\
(10000)\end{array}$ \\
\hline
\end{tabular}

Lors du stockage à $4^{\circ} \mathrm{C}$, le développement de la F.A.M. (fig. 1A) présente une phase de latence, plus importante dans le lait que dans le rétentat, qui est respectivement de $72 \mathrm{~h}$ et de $48 \mathrm{~h}$. Pour des températures plus élevées, cette phase de latence diminue et devient ainsi inférieure à $24 \mathrm{~h}$ à $12^{\circ} \mathrm{C}$, aussi bien dans le lait que dans le rétentat. Après $24 \mathrm{~h}$ de stockage, nous observons dans le lait gardé à $4^{\circ} \mathrm{C}$ et plus particulièrement dans le lait et le rétentat à $7^{\circ} \mathrm{C}$, une diminution notable de la population bactérienne, phénomène plus marqué dans le rétentat que dans le lait, puisque les taux de multiplication bactérienne sont respectivement de 0,44 et de 0,64. Pour des durées de stockage plus longues, les variations de ces taux, en fonction de la durée et de la température d'incubation, sont conformes aux études de croissance bactérienne et traduisent un développement plus intense de la F.A.M. dans le lait, aux températures de 7 et $12^{\circ} \mathrm{C}$, tandis qu'à $4^{\circ} \mathrm{C}$ la croissance de cette flore est plus importante dans le rétentat. 
La multiplication notable de la F.A.M., même aux températures de réfrigération, permet de supposer qu'elle est constituée, en proportion elevée, d'espèces psychrotrophes.

\subsubsection{Flore aérobie psychrotrophe}

Comparativement à la F.A.M., et malgré une population initiale quatre à cinq fois plus faible, aussi bien dans le lait que dans le rétentat, respectivement $2,8.10^{3}$ et $2,7.10^{4}$ bactéries par $\mathrm{ml}$, nous observons un raccourcissement de la phase de latence de $24 \mathrm{~h}$ à la température de $4^{\circ} \mathrm{C}$ et une croissance intense après seulement $24 \mathrm{~h}$ à $7^{\circ} \mathrm{C}$ ou après quelques heures de stockage à $12^{\circ} \mathrm{C}$ (fig. $1 \mathrm{~B}$ ).

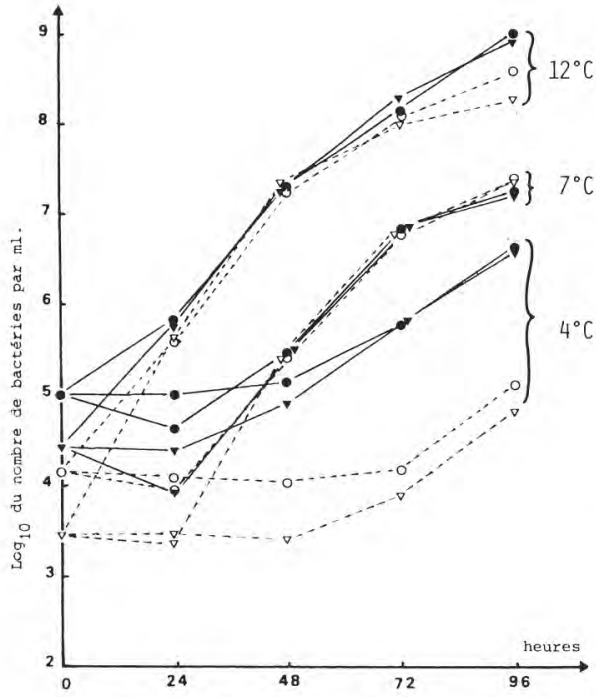

fig. $1 \mathrm{~A}$

Evolution de la flore aérobie mésophile $(\bullet, 0)$ et de la flore aérobie psychrotrophe $(\nabla, \nabla)$ dans le lait $(-$.$) et le rétentat (\longrightarrow)$ crus, stockés à $4^{\circ} \mathrm{C}, 7^{\circ} \mathrm{C}$ et $12^{\circ} \mathrm{C}$.

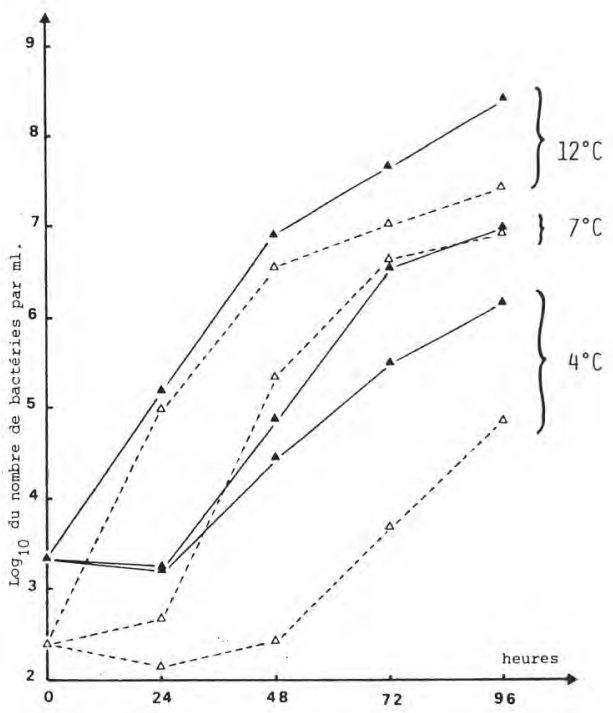

fig. $1 \mathrm{~B}$

Evolution de la flore aérobie psychrotrophe caséolytique $(\triangle, \mathbf{\Delta})$ dans le lait $(\ldots)$ et le rétentat $\left(\longrightarrow\right.$ crus stockés à $4^{\circ} \mathrm{C}$, $7^{\circ} \mathrm{C}$ et $12^{\circ} \mathrm{C}$.

Dans le rétentat stocké $24 \mathrm{~h}$ à $7^{\circ} \mathrm{C}$, nous notons, comme pour la F.A.M., une diminution significative du nombre des bactéries psychrotrophes. La présence de cette phase d'inhibition permet d'observer des niveaux de population identiques, dans le rétentat, après $36 \mathrm{~h}$ de stockage aux températures de 4 et de $7^{\circ} \mathrm{C}$. 
Comme pour la F.A.M., les taux de multiplication bactérienne sont plus importants dans le lait que dans le rétentat stockés à 7 et à $12^{\circ} \mathrm{C}$, tandis que l'observation inverse est faite à $4^{\circ} \mathrm{C}$; les valeurs élevées de ces taux traduisent la faculté de cette flore de se développer relativement rapidement aux températures de réfrigération (tab. 3).

\section{TABLEAU 3}

Taux de multiplication de la flore aérobie psychrotrophe dans le lait et le rétentat réfrigérés

\begin{tabular}{|c|c|c|c|c|c|}
\hline \multicolumn{6}{|c|}{ Durées de stockage } \\
\hline \multicolumn{6}{|c|}{ Echantillons } \\
\hline $4^{\circ} \mathrm{C}$ & $\begin{array}{l}\text { lait } \\
\text { rétentat }\end{array}$ & $\begin{array}{c}1 \\
0,93\end{array}$ & $\begin{array}{l}0,90 \\
2,7\end{array}$ & $\begin{array}{r}5,8 \\
22,2\end{array}$ & $\begin{array}{r}24,6 \\
141\end{array}$ \\
\hline $7^{\circ} \mathrm{C}$ & $\begin{array}{l}\text { lait } \\
\text { rétentat }\end{array}$ & $\begin{array}{l}0,86 \\
0,34\end{array}$ & $\begin{array}{l}104 \\
8,90\end{array}$ & $\begin{array}{r}2286 \\
263\end{array}$ & $\begin{array}{l}7857 \\
1074\end{array}$ \\
\hline $12^{\circ} \mathrm{C}$ & $\begin{array}{l}\text { lait } \\
\text { rétentat }\end{array}$ & $\begin{array}{r}150 \\
23\end{array}$ & $\begin{array}{l}7857 \\
1185\end{array}$ & $\begin{array}{r}33929 \\
7407\end{array}$ & $\begin{array}{l}62143 \\
30741\end{array}$ \\
\hline
\end{tabular}

Compte tenu des variations importantes dans les compositions des flores des rétentats, le développement des principales espèces identifiées au cours du stockage est étudié séparément, pour chaque échantillon considéré.

Le comportement des trois espèces qui constituent la flore psychrotrophe dominante, P. fluorescens (biotype I), P. putida et Acinetobacter calcoaceticus est rapporté dans la figure 2 . Bien que le taux de multiplication cellulaire, à la température de $4^{\circ} \mathrm{C}$, soit légèrement supérieur pour l'espèce $P$. fluorescens, nous pouvons néanmoins considérer que les développements bactériens de ces trois souches sont sensiblement analogues, dans nos conditions expérimentales, ce qui tendrait à montrer que la croissance de $P$. fluorescens, espèce caséolytique, est aussi importante que celle de $P$. putida et d'Acinetobacter calcoaceticus, espèces n'élaborant pas de protéases. Baumann [5] rapporte cependant que 15 p. 100 des bactéries du genre Acinetobacter montrent une activité protéolytique. 

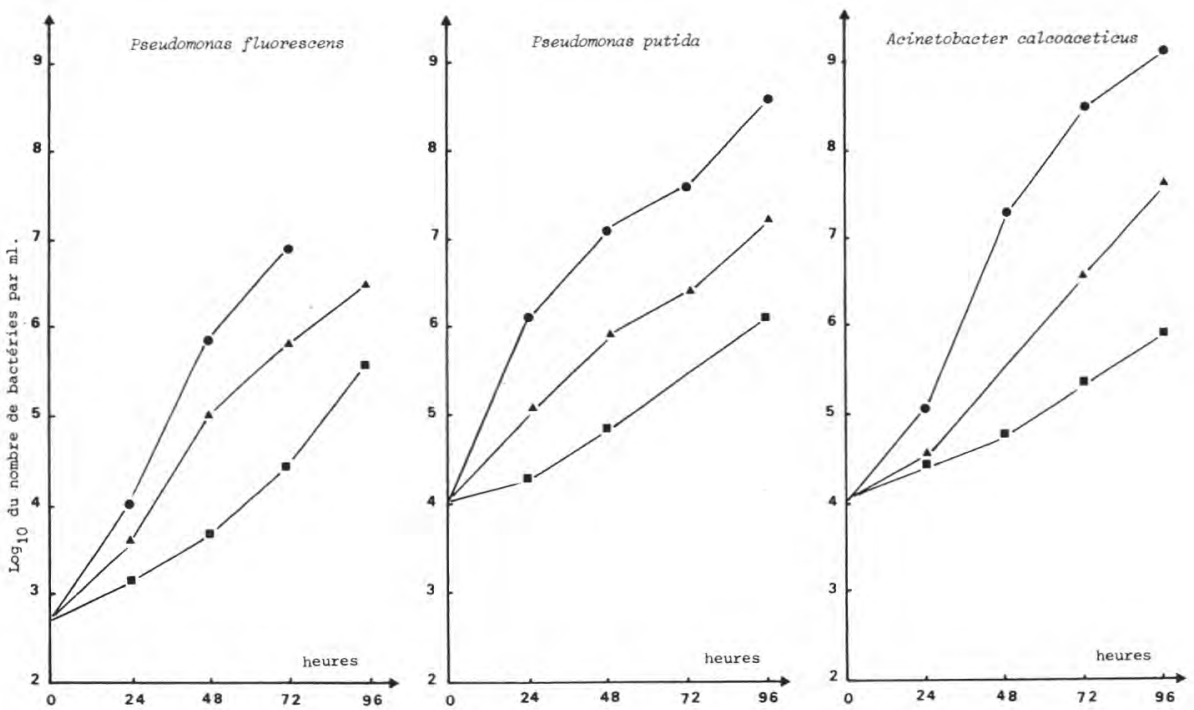

fig. 2

Développements bactériens des espèces Pseudomonas fluorescens, Pseudomonas putida et Acinetobacter calcoaceticus, dans le rétentat cru aux températures de $4^{\circ} \mathrm{C}(\boldsymbol{\bullet}), 7^{\circ} \mathrm{C}(\boldsymbol{\Delta})$ et $12^{\circ} \mathrm{C}(\bullet)$.

Nous n'observons pas, aux températures de 4 et de $7^{\circ} \mathrm{C}$, après $24 \mathrm{~h}$ de stockage, d'inhibition dans la multiplication cellulaire; ces trois espèces se développent relativement rapidement et sont en phase exponentielle de croissance après moins de $24 \mathrm{~h}$ à $7^{\circ} \mathrm{C}$ et après environ $24 \mathrm{~h}$ à $4^{\circ} \mathrm{C}$, tandis qu'à $12^{\circ} \mathrm{C}$, la phase de latence n'est pas notée.

Le caractère psychrotrophe de l'espèce $P$. fluorescens est rapporté par de nombreux auteurs et notamment par Thomas et Druce [80] qui indiquent, qu'après $10 \mathrm{j}$ de stockage au froid, cette espèce et plus précisément les biotypes I et II dominent dans le lait $\mathrm{cru}$, et par Bloquel [8] qui isole également $P$. fluorescens biotype I, principale bactérie d'un lait paucimicrobien stocké pendant 4 j à $4^{\circ} \mathrm{C}$.

En plus de ces trois espèces, nous identifions également d'autres bactéries gram-négatives, telles que des espèces élaborant un pigment caroténoïde de couleur orange, Flavobacterium $\mathrm{II}_{\mathrm{B}}$, Flavobacterium $I I_{F}, V E-2$, des bactéries appartenant aux genres Pseudomonas ( $P$. stutzeri, $P$. pseudo-alcaligenes) et Aeromonas, et aux espèces Enterobacter cloacae et Klebsiella pneumoniae.

Nos résultats sont à rapprocher de très nombreux travaux qui rapportent également la prédominance, dans le lait réfrigéré, des 
genres Pseudomonas, Acinetobacter et de quelques bactéries coliformes $[8,10,20,46,63,76,80,82]$.

\subsubsection{Flore aérobie psychrotrophe caséolytique}

Les allures des courbes traduisant le développement bactérien de la flore psychrotrophe caséolytique (fig. 1 B), au cours du stockage, sont semblables à celles obtenues pour la flore psychrotrophe et montrent des phases de latence de durées équivalentes. Cependant la comparaison des taux de multiplication bactérienne de ces deux flores (tab. 3 et 4) traduit un meilleur développement des espèces caséolytiques aux températures de réfrigération. Comme pour les flores examinées précédemment, ces taux sont plus élevés dans le lait que dans le rétentat stockés à 7 et à $12^{\circ} \mathrm{C}$, tandis qu'à $4^{\circ} \mathrm{C}$, nous observons un résultat inverse.

\section{TABLEAU 4}

Taux de multiplication de la flore aérobie psychrotrophe caséolytique dans le lait et le rétentat réfrigérés

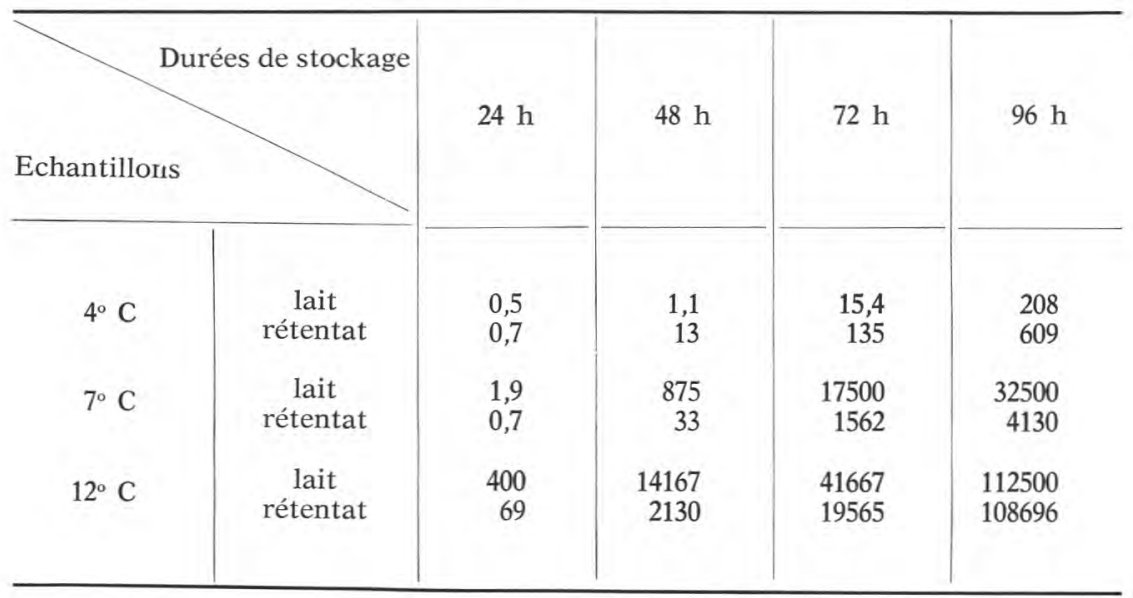

L'espèce $P$. fluorescens, biotype I est la principale espèce identifiée dans les rétentats crus stockés à 4,7 et $12^{\circ} \mathrm{C}$ jusqu'à $96 \mathrm{~h}$. Nous identifions moins fréquemment d'autres espèces, telles que Flavobacterium $\mathrm{II}_{\mathrm{B}}, V E-2$, des Pseudomonas fluorescens apigmentés, des Xanthomonas et des Enterobacter cloacae.

Dans de nombreux travaux, $P$. fluorescens constitue également la flore psychrotrophe caséolytique dominante des laits réfrigérés $[9$, $37,38,60,75,79]$. 
Malgré des niveaux de population sensiblement identiques dans le lait et dans le rétentat, dès $24 \mathrm{~h}$ de stockage, d'une part à $7^{\circ} \mathrm{C}$ et d'autre part à $12^{\circ} \mathrm{C}$ (fig. $1 \mathrm{~B}$ ) et une population bactérienne vingt fois plus importante dans le rétentat que dans le lait conservés à $4^{\circ} \mathrm{C}$ pendant $96 \mathrm{~h}$, respectivement $1,4.10^{6}$ et $6,9.10^{4}$ bactéries par $\mathrm{ml}$, Garcia-Ortiz [24] en effectuant des analyses chimiques sur ces échantillons, rapporte que l'augmentation du taux en protéines solubles est, pour toutes les températures considérées, plus importante dans le lait que dans le rétentat après 4 jours de stockage. Si l'on admet que les modifications physico-chimiques provoquées par le froid sont plus marquées dans le lait que dans le rétentat, l'obtention d'une dispersion de micelles de caséine de taille plus réduite, dans le lait, et l'augmentation de la solubilité de la phase colloïdale, plus particulièrement de la caséine $\beta$, faciliteraient l'action des protéases bactériennes.

\subsubsection{Flore coliforme}

Les numérations de la flore coliforme sur milieu au désoxycholate lactose-agar et sur milieu lactosé bilié au vert brillant donnent des résultats équivalents, puisque le facteur de corrélation, entre 135 couples de valeurs, est $r=0,92$.

Les dénombrements réalisés sur milieu au vert brillant (tab. 5) traduisent un développement lent des bactéries coliformes, aussi bien dans le lait que dans le rétentat, à la température de $4^{\circ} \mathrm{C}$. Cette observation concorde avec les travaux de Mc Kenzie et Robinson [55] qui rapportent une multiplication considérable de ces bactéries dans

\section{TABLEAU 5}

Taux de multiplication de la flore coliforme dans le lait et le rétentat réfrigérés

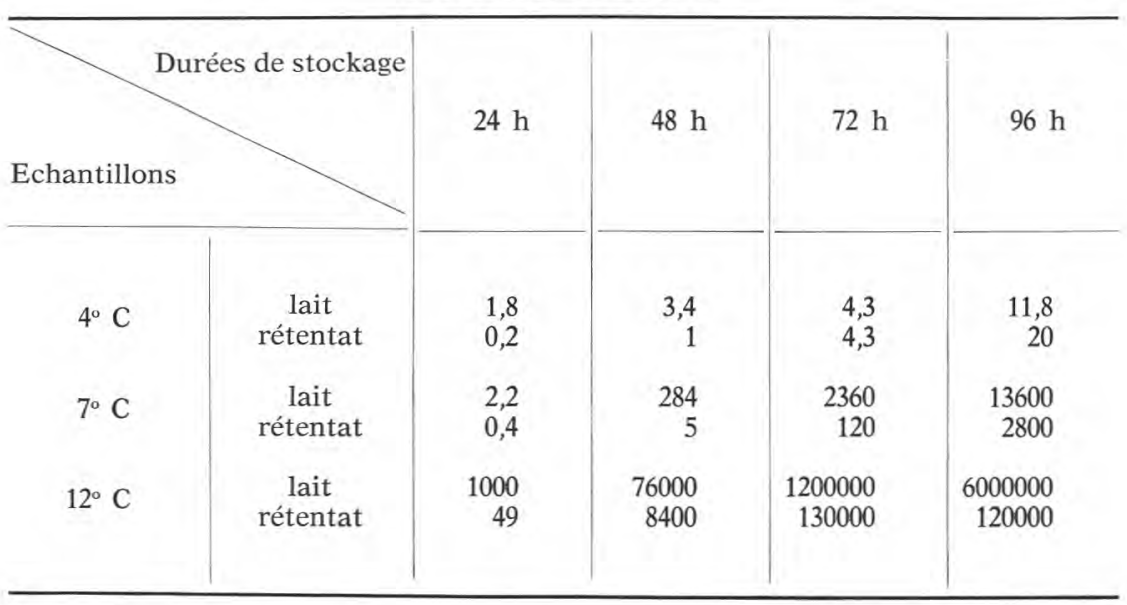


le lait contenant moins de $1.10^{2}$ bactéries par ml, après $24 \mathrm{~h}$ de stockage à $10^{\circ} \mathrm{C}$, et aucun développement à $4^{\circ} \mathrm{C}$ pendant la même durée.

Dans le rétentat (fig. 3), nous notons une inhibition importante de la croissance des bactéries coliformes, après $24 \mathrm{~h}$ de stockage aux températures de 4 et de $7^{\circ} \mathrm{C}$. Des niveaux de population sensiblement identiques sont atteints, dans le lait et dans le rétentat, après seulement $24 \mathrm{~h}$ de stockage à $12^{\circ} \mathrm{C}$ et $48 \mathrm{~h}$ à $7^{\circ} \mathrm{C}$, malgré une contamination initiale quarante fois plus faible dans le lait. Le développement bactérien est favorisé dans le lait aux températures de 7 et $12^{\circ} \mathrm{C}$, tandis qu'à $4^{\circ} \mathrm{C}$, dans le rétentat, après une inhibition importante, la vitesse de croissance est supérieure à celle mesurée dans le lait.

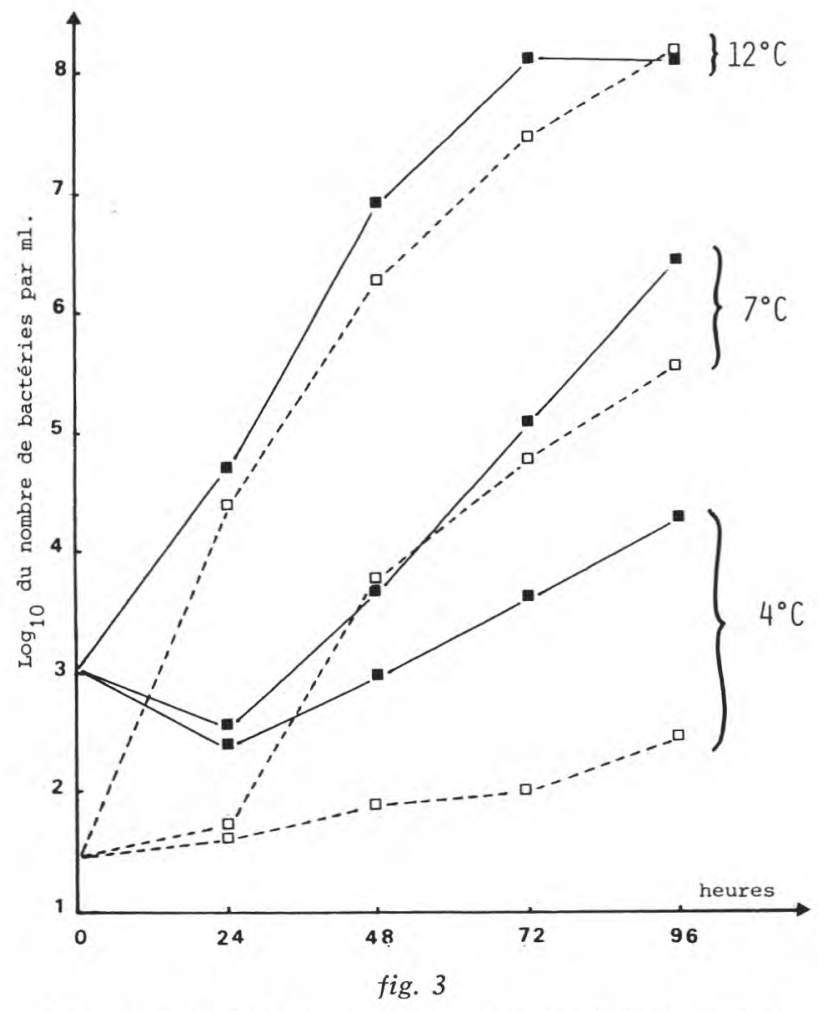

Evolution de la flore coliforme dans le lait (--) et le rétentat crus $(-)$, stockés à $4^{\circ} \mathrm{C}, 7^{\circ} \mathrm{C}$ et $12^{\circ} \mathrm{C}$.

Comparativement aux autres flores, la flore coliforme montre les taux de multiplication cellulaire les plus importants à la température de $12^{\circ} \mathrm{C}$; ce résultat, en partie en relation avec un taux de contamination initiale très faible [21] $(0,2$ et 1 p. 100 respectivement dans le lait et dans le rétentat), est dû principalement à la présence d'une 
proportion notable d'espèces psychrotrophes-mésophiles. Comme le confirment les taux de multiplication à 4 et à $7^{\circ} \mathrm{C}$, cette flore est également capable de se développer à des températures inférieures ou égales à $5^{\circ} \mathrm{C}[65,82]$.

L'identification de 630 souches d'entérobactéries, isolées de rétentats crus stockés à 4,7 et $12^{\circ} \mathrm{C}$ jusqu'à $96 \mathrm{~h}$, montre que les espèces les plus fréquemment isolées sont, par ordre décroissant, E. coli, Enterobacter cloacae, Citrobacter intermedium, Enterobacter hafniae, Klebsiella pneumoniae et $C$. freundii, classement qui correspond à celui réalisé avant le stockage du rétentat. Cependant, après $96 \mathrm{~h}$ de stockage aux températures de 4 et $7^{\circ} \mathrm{C}$, les principales espèces coliformes sont identifiées à E. cloacae, E. hafniae et $K$. pneumoniae, et à la température de $12^{\circ} \mathrm{C}$, à $K$. pneumoniae, aux espèces du genre Enterobacter, à $E$. coli, à $C$. freundii et à $C$. intermedium. La proportion de l'espèce $E$. coli, initialement principale bactérie du lait et du rétentat, avant stockage, diminue au cours des divers barèmes d'entreposage, car cette espèce mésophile ne se développe que très lentement à $12^{\circ} \mathrm{C}$.

Les comportements d'E. cloacae et de $K$. pneumoniae, dans le rétentat stocké jusqu'à 96 h (fig. 4), traduisent le caractère psychro-
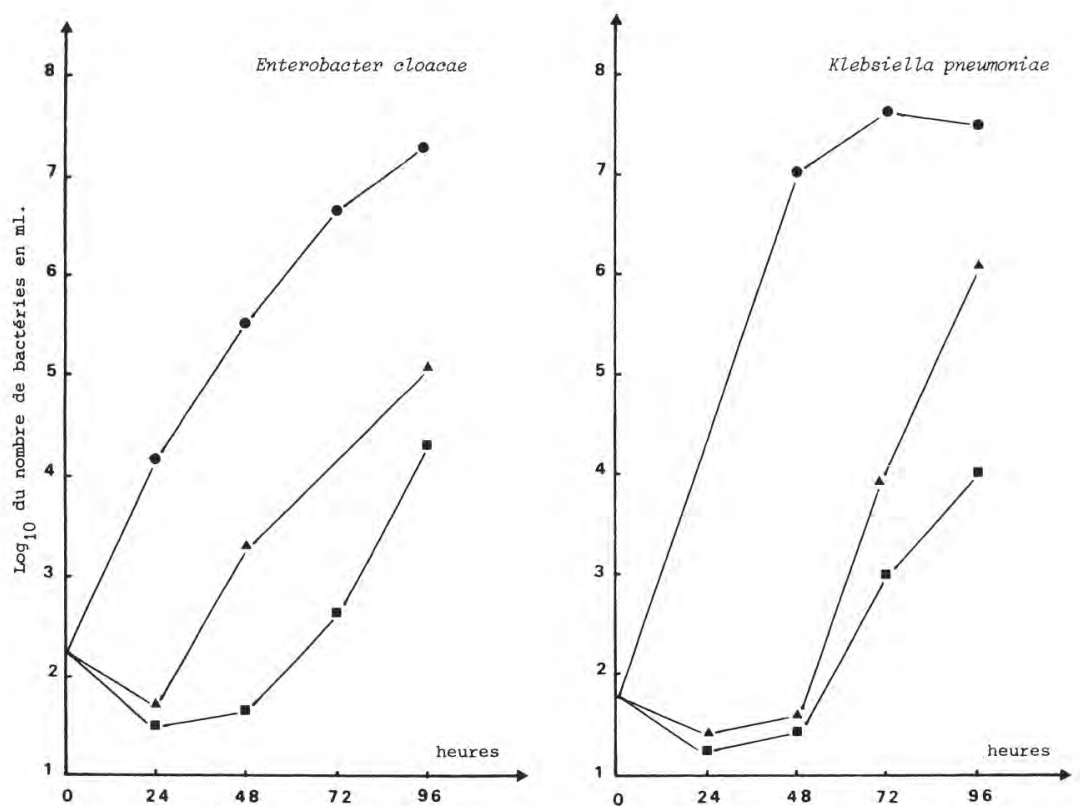

fig. 4

Développements bactériens de souches coliformes, Enterobacter cloacae, Klebsiella pneumoniae, dans le rétentat cru aux températures de $4^{\circ} \mathrm{C}(\mathbf{m}), 7^{\circ} \mathrm{C}(\mathbf{\Lambda})$ et $12^{\circ} \mathrm{C}(\bullet)$. 
trophe de ces espèces, caractère sensiblement plus marqué pour $l^{\prime}$ espèce $E$. cloacae, puisque la phase de latence à $7^{\circ} \mathrm{C}$ ne dure que $24 \mathrm{~h}$ contre $48 \mathrm{~h}$ environ pour l'espèce $K$. pneumoniae. Le début du stockage du rétentat se traduit, aux températures de 4 et de $7^{\circ} \mathrm{C}$ pendant $24 \mathrm{~h}$, par une phase d'inhibition importante dont l'intensité varie avec la température appliquée, tandis qu'à $12^{\circ} \mathrm{C}$, ces espèces psychrotrophes-mésophiles sont très rapidement en phase exponentielle de croissance. La faculté de ces espèces de se développer aux températures de réfrigération est rapportée dans divers travaux. C'est ainsi que Greene et Jezeski [28] ne trouvent pas de différences significatives entre les temps de génération de souches de Pseudomonas et d'Enterobacter à $5^{\circ} \mathrm{C}$. Enterobacter cloacae, considérée comme bactérie psychrotrophe vraie [65], représente l'espèce dominante du lait cru [76], et après un stockage de $72 \mathrm{~h}$, entre 3 et $5^{\circ} \mathrm{C}$, elle constitue avec $K$. pneumoniae 88 p. 100 de la flore coliforme [64]. D'autres espèces sont également psychrotrophes, telles que $E$. hafniae [34], E. aerogenes [64], Citrobacter freundii [81, 82], et Serratia marcescens [57].

\subsection{Relations entre les différentes flores}

2.3.1. Rapport entre la flore aérobie psychrotrophe et la F.A.M.

$\mathrm{Au}$ cours du stockage, nous constatons une augmentation, par rapport à la F.A.M., de la proportion des bactéries psychrotrophes. Ce pourcentage initialement égal à 20 et à 27 p. 100 , respectivement dans le lait et dans le rétentat, varie selon les barèmes de stockage appliqués. C'est ainsi que la F.A.M. est constituée, après $48 \mathrm{~h}$ à $72 \mathrm{~h}$ à $7^{\circ} \mathrm{C}, 72 \mathrm{~h}$ à $4^{\circ} \mathrm{C}$ et après seulement quelques heures de stockage à $12^{\circ} \mathrm{C}$, en majorité de bactéries psychrotrophes. Cependant, dans le lait, après $72 \mathrm{~h}$ de stockage à $12^{\circ} \mathrm{C}$, la diminution du pourcentage des bactéries psychrotrophes est en relation avec le développement d'espèces mésophiles, bactéries qui montrent une phase de latence relativement longue à $12^{\circ} \mathrm{C}$. Des proportions supérieures à $100 \mathrm{p} .100$ pourraient sembler aberrantes, mais ce résultat provient du fait que certaines espèces psychrotrophes présentent une croissance moindre à $30^{\circ} \mathrm{C}$ et que la numération de la flore aérobie mésophile ne traduit aucunement le dénombrement de la «flore totale aérobie ».

\subsubsection{Rapport entre la flore psychrotrophe caséolytique et la flore psychrotrophe}

Ces pourcentages ne sont donnés qu'à titre indicatif, car les numérations des flores caséolytiques et celles n'élaborant pas de protéases, sont réalisées sur deux milieux, respectivement la gélose au lait et la Tryptone-Agar de la F.I.L., qui, différant par leurs facteurs de croissance, modifient le comportement des souches examinées.

Si à l'origine, la flore caséolytique représente 8,5 p. 100 de la flore aérobie, aussi bien dans le lait que dans le rétentat, elle atteint, 
dans le lait stocké pendant 48 h à $7^{\circ} \mathrm{C}$ ou $96 \mathrm{~h}$ à $4^{\circ} \mathrm{C}, 70 \mathrm{p} .100$ contre environ $35 \mathrm{p} .100$ dans le rétentat. A $12^{\circ} \mathrm{C}$, cette proportion ne dépasse pas $25 \mathrm{p} .100$, après $4 \mathrm{j}$, car cette température permet également le développement d'espèces psychrotrophes non caséolytiques appartenant notamment à la famille des Enterobacteriaceae.

2.3.3. Rapport entre la flore coliforme et les flores aérobies mésophile et psychrotrophe

Les variations des pourcentages, dans le lait et dans le rétentat, de la flore coliforme dans chacune de ces deux flores sont sensiblement identiques.

Le taux de contamination en bactéries coliformes ne varie pratiquement pas pendant toute la durée du stockage du lait, à 4 et à $7^{\circ} \mathrm{C}$, et reste voisin de $1 \mathrm{p} .100$. Dans les mêmes conditions d'entreposage, ce taux diminue dans le rétentat de 3,7 p. 100 à respectivement $0,5 \mathrm{p} .100$ et $1 \mathrm{p} .100$, à 4 et à $7^{\circ} \mathrm{C}$, après $4 \mathrm{j}$, malgré des taux de multiplication cellulaire de 20 et de 2800 . Ces résultats confirment le caractère psychrotrophe des bactéries coliformes, mais aux températures de réfrigération, leurs temps de génération restent plus longs que ceux d'autres genres bactériens. Cependant, même si elles sont rarement considérées comme des bactéries psychrophiles vraies, et même comme des psychrotrophes par certains auteurs, Eddy et Nakae [61] les classent parmi les mésophiles psychrotrophes.

Comme le confirment divers travaux, les bactéries coliformes, dans le lait cru et donc également dans le rétentat, se multiplient lentement à des températures comprises entre 1,5 et $5^{\circ} \mathrm{C}[21,23,46$, 64], plus activement à $7^{\circ} \mathrm{C}$ [64], mais d'une manière générale, ne prédominent jamais à des températures de stockage inférieures à 8 ou à $10^{\circ} \mathrm{C}[65]$.

\subsection{Evolution de l'acidité du rétentat et du lait pendant le stockage}

Les courbes traduisant les variations de l'acidité titrable et du $\mathrm{pH}$ (fig. 5) montrent que dans le lait et le rétentat stockés à 4 et à $7^{\circ} \mathrm{C}$ pendant $4 \mathrm{j}$, il n'y a pas de modification sensible de l'acidité initiale. Ce résultat est en relation avec un développement faible ou nul des bactéries acidifiantes, et il est à noter que la multiplication cellulaire importante des espèces caséolytiques ne provoque pas d'alcalinisation.

A la température de $12^{\circ} \mathrm{C}$, l'abaissement notable du $\mathrm{pH}$ après $72 \mathrm{~h}$ de stockage devient, après $96 \mathrm{~h}$, plus important dans le rétentat que dans le lait malgré un effet tampon plus grand dans le rétentat. Cette acidification est en relation avec la teneur importante, environ 25 à $30 \mathrm{p} .100$, en bactéries coliformes et avec le développement d'autres espèces mésophiles acidifiantes.

Il convient de signaler que la valeur anormalement élevée du pH initial, dans le lait, est due à l'apport dans l'alimentation du troupeau de substances riches en urée. 


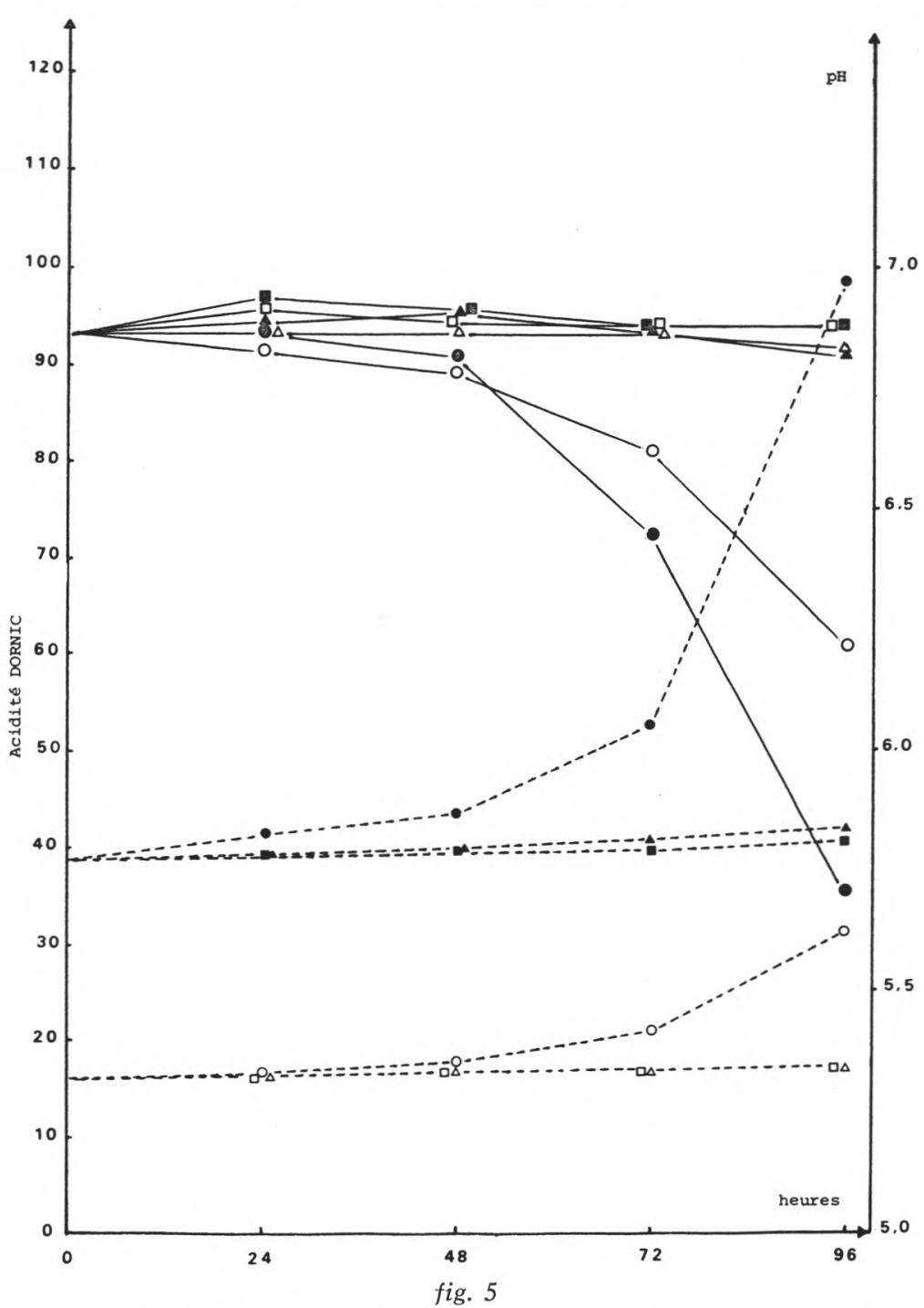

Evolution de l'acidité Dornic (--) et du $\mathrm{pH}(-)$ dans le lait et le rétentat crus. Echantillons de lait à $4^{\circ} \mathrm{C}(\square), 7^{\circ} \mathrm{C}(\triangle)$ et $12^{\circ} \mathrm{C}(0)$ et de rétentat à $4^{\circ} \mathrm{C}$ $(\bullet), 7^{\circ} \mathrm{C}(\boldsymbol{\Delta})$ et $12^{\circ} \mathrm{C}(\bullet)$.

\section{DISCUSSION GENERALE}

Un lait cru paucimicrobien, contenant à l'origine $1,4.10^{4}$ bactéries par $\mathrm{ml}$, soumis à l'ultrafiltration réalisée à une température de $35^{\circ} \mathrm{C}$ 
pendant environ $1 \mathrm{~h}$, voit, en raison d'un taux de concentration de quatre fois en poids et d'une prolifération bactérienne notable, sa flore bactérienne se multiplier par un facteur compris entre 7 et 10 pour les flores aérobies mésophile et psychrotrophe et par 40 pour la flore coliforme. L'entreposage du rétentat, aux températures de 4 , 7et $12^{\circ} \mathrm{C}$, montre que la F.A.M. atteint après $96 \mathrm{~h}$ respectivement $4,4.10^{6}, 3,2.10^{7}$ et $1.10^{9}$ bactéries par ml.

Si l'on considère, comparativement au lait, qu'un rétentat contenant environ $5.10^{6}$ bactéries par $\mathrm{ml}$ peut encore être utilisé en fabrication fromagère, car l'augmentation de l'acidité titrable n'est que de 7 p. 100 (2 à $\left.3^{\circ} \mathrm{D}\right)$ et qu'il n'y a pas variation du $\mathrm{pH}$, les durées de stockage permettant d'atteindre ce seuil sont de $96 \mathrm{~h}$ à $4^{\circ} \mathrm{C}, 72 \mathrm{~h}$ à $7^{\circ} \mathrm{C}$ et entre 24 à $48 \mathrm{~h}$ à $12^{\circ} \mathrm{C}$. Cependant une réduction de $24 \mathrm{~h}$ de la durée de stockage semblerait plus acceptable. Dans ces conditions, la F.A.M., comprise entre $3.10^{5}$ et $6,5.10^{5}$ bactéries par $\mathrm{ml}$, est constituée presque exclusivement d'espèces psychrotrophes, avec une proportion non négligeable d'espèces caséolytiques (tab. 6).

\section{TABLEAU 6}

Composition de la flore bactérienne du rétentat après divers barèmes de stockage

\begin{tabular}{|c|c|c|c|}
\hline Barèmes de stockage & $4^{\circ} \mathrm{C}-72 \mathrm{~h}$ & $7^{\circ} \mathrm{C}-48 \mathrm{~h}$ & $12^{\circ} \mathrm{C}-24 \mathrm{~h}$ \\
\hline Flore aérobie mésophile & $6.10^{5}$ & $3.10^{5}$ & $6,5.10^{5}$ \\
\hline $\begin{array}{l}\text { Flore aérobie psychrotrophe/ } \\
\text { F.A.M. (p. 100) }\end{array}$ & 100 & 100 & 95 \\
\hline $\begin{array}{l}\text { Flore caséolytique/F. psychro- } \\
\text { trophe (p. 100) }\end{array}$ & 52 & 32 & 25 \\
\hline Flore coliforme/F.A.M. (p.100) & 0,7 & 1,7 & 7,5 \\
\hline
\end{tabular}

Si nous choisissons la température de $4^{\circ} \mathrm{C}$ pour le stockage du rétentat, nous constatons que le taux de multiplication bactérienne, après $72 \mathrm{~h}$ est de 6 pour la F.A.M., de 4,3 pour la flore coliforme et de 22 pour la flore psychrotrophe. Dans ces conditions, les bactéries psychrotrophes caséolytiques ( $P$. fluorescens, Flabobacterium $\mathrm{II}_{\mathrm{B}}$, 
E. cloacae, E. hafniae, $K$. pneumoniae), présentent un taux de multiplication supérieur à 100 .

Comparativement au lait, la multiplication bactérienne de toutes les flores examinées est plus importante, à la température de $4^{\circ} \mathrm{C}$, dans le rétentat, alors que nous observons un résultat inverse à 7 et à $12^{\circ} \mathrm{C}$. Dans le rétentat, l'inhibition de la croissance de toutes les flores et plus particulièrement des espèces coliformes, dès le début du stockage aux températures de 4 et de $7^{\circ} \mathrm{C}$, serait due à la concentration, lors de l'ultrafiltration, des substances bactéricides du lait cru, composés ayant un poids moléculaire voisin ou supérieur au seuil de coupure de la membrane.

Dans le lait, ce phénomène a été observé par divers auteurs [59]. C'est ainsi que Jaquet et Thévenot [33] mentionnent que la phase bactéricide persiste dans le lait fraîchement trait pendant une période brève variant de 4 à $6 \mathrm{~h}$ lorsque la température est de $35^{\circ} \mathrm{C}$, mais relativement longue, près de $24 \mathrm{~h}$, lorsque ce même lait est refroidi. Selon Malling-Olseon cité par Panes et Thomas [64], des cultures de bactéries coliformes se développent dix à cent fois mieux dans le lait pasteurisé que dans le lait cru, car les substances inhibitrices sont dénaturées par le traitement thermique $[4,69]$.

Récemment Reitter [73] a classé le système antimicrobien du lait cru en deux groupes : d'une part les substances ayant une action spécifique telles que les immunoglobulines et les phagocytes et, d'autre part celles n'en possédant pas tel que le lysozyme, la lactoferrine et la lactoperoxydase/thiocyanate $/ \mathrm{H}_{2} \mathrm{O}_{2}$. Dans ce domaine, les travaux de nombreux chercheurs sont fondamentaux $[2,4,7,43$, $69,85,88]$.

L'ultrafiltration à l'usine de lait cru, écrémé ou non, permet d'obtenir un rétentat, concentré protéique ou préfromage liquide dont le taux en protéines, par rapport au lait d'origine est multiplié par un facteur compris entre 2 et 5 . Sa transformation, selon une technologie appropriée, en caillé partiellement ou totalement égoutté a permis de réaliser, soit à titre expérimental, soit à titre industriel, différents types de fromages, tels que des pâtes fraîches $[11,13,15$, $16,17,47,52,53,62,86,87]$, des pâtes molles [1, 49, 50, 71, 72], des pâtes persillées $[35,45)$, des fromages fondus [48], différents fromages étrangers $[6,12,14,25,29,31,54,58,74,84]$, des poudres de préfromages [27] et du lait concentré [77].

L'intérêt de l'ultrafiltration, sur le plan technologique, est d'augmenter le rendement fromager jusqu'à 22 à 24 p. 100 en fabrication de Camembert [71] ou même jusqu'à 30 p. 100 pour celle du Fêta [29], de standardiser les poids de fromages par une mécanisation plus accrue [32] et de réduire les quantités de ferments et de présure à utiliser [49].

Sur le plan nutritionnel, la rétention des protéines du lactosérum améliore la qualité des produits finis et la diminution de la teneur 
en lactose les rend consommables par les individus ne tolérant pas ce sucre $[18,19,42,44]$.

D'autre part, sur le plan économique, l'avantage de ce procédé est lié à la transformation de rétentat de volume inférieur à celui du lait d'origine. Jusqu'à présent l'ultrafiltration du lait est réalisée à l'usine, mais son utilisation à la ferme pourrait entraîner une diminution importante des capacités des installations de stockage, de transport, de réception et de traitement du rétentat et en conséquence une réduction notable des besoins énergétiques [22].

Dans l'hypothèse où l'installation de modules d'ultrafiltration à la ferme et le stockage du rétentat cru, en tanks réfrigérés, seraient des opérations économiquement rentables, seuls les laits de qualité satisfaisante, c'est-à-dire contenant moins de $5.10^{4}$ bactéries aérobies mésophiles par $\mathrm{ml}$, pourraient être concentrés. En effet, d'après nos conditions opératoires, la charge bactérienne plus de dix fois plus importante dans le rétentat concentré, quatre fois dans le lait d'origine entraîne une diminution des durées d'entreposage au froid. De plus, lors de l'utilisation répétée du module à la ferme, il faudra tenir compte également de la présence d'une flore de contamination dont l'importance, variable selon l'état sanitaire de l'appareillage, réduira encore l'intérêt de la réfrigération. Si par analogie au lait nous retenons une température de réfrigération de $4^{\circ} \mathrm{C}$, le rétentat ne peut être stocké que pendant $72 \mathrm{~h}, 96 \mathrm{~h}$ au maximum, mais ces durées ne tiennent pas compte des apports successifs, deux par jour, de rétentat tiède à une température voisine de $35^{\circ} \mathrm{C}$. Des températures comprises entre 2 et $3^{\circ} \mathrm{C}$ seraient donc à retenir pour le stockage du rétentat cru pendant $3 \mathrm{j}$. Cependant, compte tenu d'un taux de contamination sensiblement voisin de $10^{5}$ bactéries par $\mathrm{ml}$ après U.F., la durée de stockage est fonction également de la composition de la flore dominante et plus particulièrement de la présence d'espèces psychrotrophes caséolytiques et lipolytiques. Si les altérations de la structure physicochimique des principaux constituants du rétentat, après $96 \mathrm{~h}$ de stockage à $4^{\circ} \mathrm{C}$, ou pendant $72 \mathrm{~h}$ à $7^{\circ} \mathrm{C}$, restent toutefois très limitées et même si sur le plan sanitaire, la présence massive d'espèces psychrotrophes ne pose pas de problèmes majeurs, car cette flore est rapidement détruite par un traitement thermique peu sévère, comme une pasteurisation à $72^{\circ} \mathrm{C}$ pendant $20 \mathrm{~s}$, leurs protéases et leurs lipases, élaborées pendant le stockage et présentant une certaine thermostabilité, peuvent être à l'origine, dans les produits laitiers pasteurisés, de modifications indésirables entraînant des difficultés dans les processus de fabrication et des anomalies de maturation des fromages.

La multiplication bactérienne pendant l'ultrafiltration pourrait être limitée en travaillant soit à des températures de réfrigération, soit à des températures inhibant le développement des flores psychrotrophes et mésophiles, températures supérieures à $40^{\circ} \mathrm{C}$, mais ne provoquant pas de modification physicochimique du rétentat. Cepen- 
dant, ces conditions ne semblent pas être envisageables, car aux températures de réfrigération, la durée de ce traitement serait considérablement allongée et ne serait donc pas compatible avec une utilisation répétée, et les fermes devraient s'équiper d'échangeurs de température. Dans notre expérimentation, l'ultrafiltration réalisée à $35^{\circ} \mathrm{C}$, dès la fin de la traite, sur un module de $1 \mathrm{~m}^{2}$ de surface filtrante dure $65 \mathrm{~min}$ pour une concentration du lait de quatre fois un poids. Il s'avérerait donc nécessaire de proposer toute une gamme de modules plus performants pour réduire ces durées qui ne tiennent pas compte des opérations de rinçage et de stérilisation, opérations qui conditionnent la qualité bactériologique des produits finis et donc l'intérêt de l'utilisation de cette technique à la ferme.

\section{Rés u mé}

Six échantillons de $50 \mathrm{~kg}$ de lait cru écrémé, possédant des taux de contamination en bactéries aérobies mésophiles sensiblement identiques et compris entre $1.1 .10^{4}$ et $2.10^{4}$ bactéries par $\mathrm{ml}$, sont ultrafiltrés pendant $1 \mathrm{~h}$ à la température de $35^{\circ} \mathrm{C}$.

Dans les échantillons de lait, les proportions des flores aérobies psychrotrophe, psychrotrophe caséolytique et de la flore coliforme varient très largement d'un échantillon à l'autre, mais les mêmes espèces bactériennes constituent la flore dominante. Ainsi nous identifions, dans la flore aérobie psychrotrophe, principalement Pseudomonas fluorescens, puis Flavobacterium $\mathrm{II}_{\mathrm{B}}$ et Acinetobacter calcoaceticus ; dans la flore psychrotrophe caséolytique également les espèces $P$. fluorescens et Flavobacterium $\mathrm{II}_{\mathrm{B}}$; dans la flore coliforme Escherichia coli et Enterobacter cloacae et en faibles proportions Citrobacter intermedium et Citrobacter freundii.

Au cours de l'ultrafiltration, compte tenu d'un taux de concentration de quatre fois en poids (extrait sec du rétentat de $19 \mathrm{p} .100$ ), la contamination bactérienne est multipliée par un facteur 8 pour les flores aérobies mésophile, psychrotrophe et psychrotrophe caséolytique et par 44 pour la flore coliforme.

Le stockage du rétentat aux températures de 4,7 et $12^{\circ} \mathrm{C}$ ne modifie pas la composition de la flore dominante, mais après $4 \mathrm{j}$, les niveaux de population en bactéries aérobies mésophiles sont respectivement de $4.4 .10^{6}, 3.2 .10^{7}$ et $10^{9}$ bactéries par ml. Comparativement aux autres flores, le développement des bactéries coliformes, plus faible à 4 et à $7^{\circ} \mathrm{C}$, est plus rapide à $12^{\circ} \mathrm{C}$. La multiplication bactérienne de toutes les flores est plus prononcée dans le lait que dans le rétentat, à 7 et à $12^{\circ} \mathrm{C}$, tandis qu'à $4^{\circ} \mathrm{C}$, nous observons un résultat inverse. Dans le rétentat, des inhibitions dans la croissance bactérienne sont notées après $24 \mathrm{~h}$ de stockage à $7^{\circ} \mathrm{C}$, plus particulièrement chez les bactéries coliformes, cette observation étant peut-être en relation avec une concentration, par la membrane d'ultrafiltration, de substances inhibitrices du lait cru. 
Dans le rétentat, des niveaux de population voisins de $3.10^{5}$ à 6.5.10 bactéries par $\mathrm{ml}$, se traduisant par une très faible augmentation de l'acidité (2 à 3 p. 100), sont atteints après des stockages de 72 , 48 et $24 \mathrm{~h}$ à respectivement 4,7 et $12^{\circ} \mathrm{C}$.

\section{S u m m a ry}

\section{BACTERIOLOGICAL STUDY OF MILK ULTRAFILTRATED AND OF ITS RETENTATE STORED AT $4^{\circ} \mathrm{C}$}

Six $50 \mathrm{~kg}$ samples of skimmilk, which contained nearly identical contamination levels including between $1.1 .10^{4}$ and $2.10^{4}$ of mesophilic aerobic bacteria per $\mathrm{ml}$, were ultrafiltered for one hour at $35^{\circ} \mathrm{C}$ $\left(95^{\circ} \mathrm{F}\right)$.

In the milk samples, the proportions of the psychrotrophic, caseolytic psychrotrophic aerobic flora and of the coliform flora varied very largely from one sample to another, but the same species constituted the predominant flora. Thus, in the psychrotrophic aerobic flora, we identified chiefly Pseudomonas fluorescens, then Flavobacterium $\mathrm{II}_{\mathrm{B}}$ and Acinetobacter calcoaceticus; in the caseolytic psychrotrophic flora also the species $P$. fluorescens and Flavobacterium $I I_{B}$; in the coliform flora Escherichia coli and Enterobacter cloacae and in weak proportions citrobacter intermedium and Citrobacter freundii.

During the ultrafiltration, given a concentration ratio of 1:4 (dry matter content approximately 19 p. 100), the bacterial contamination was multiplied by a factor 8 for the mesophilic, psychrotrophic and caseolytic psychrotrophic aerobic flora and by 44 for the coliform flora.

Storage of the retentate at $4^{\circ} \mathrm{C}\left(39,2^{\circ} \mathrm{F}\right), 7^{\circ} \mathrm{C}\left(44,6^{\circ} \mathrm{F}\right)$ and $12^{\circ} \mathrm{C}$ $\left(53,6^{\circ} \mathrm{F}\right)$ did not modify the composition of the dominating flora, but after 4 days, the population levels of the mesophilic aerobic bacteria were respectively $4.4 .10^{6}, 3.2 .10^{7}$ and $10^{9}$ bacteria per $\mathrm{ml}$. Comparatively with the other flora, the growth of the coliform bacteria, more weak at $4^{\circ} \mathrm{C}$ and $7^{\circ} \mathrm{C}$, was very quick at $12^{\circ} \mathrm{C}$. The bacterial multiplication of all the flora was more pronounced in the samples of milk than in the retentate at $7^{\circ} \mathrm{C}$ and $12^{\circ} \mathrm{C}$, while at $4^{\circ} \mathrm{C}$, we observed the opposite result.

In the retentate, inhibitions in the bacterial growth were noted after 24 hours of storage at $7^{\circ} \mathrm{C}$, more particularly with coliform bacteria, this observation perhaps being related to a concentration of inhibitric substances from raw milk by the membrane ultrafiltration.

In the retentate, some population levels near $3.10^{5}$ to $6.10^{5}$ bacteria per $\mathrm{ml}$, as manifested by a very weak increase of the measurable acidity ( 2 to $3 \mathrm{p} .100$ ), were attained after storages for 72,48 and 24 hours at 4,7 and $12^{\circ} \mathrm{C}$ respectively. 


\section{Bibliographie}

[1] Abd-el-Salam (M. H.), Magmoush (M. R.), Sleem (R.), El-Abd (M.) (1978). $X X^{\mathrm{e}}$ Congr. Int. Lait., F, 811-812.

[2] Alais (C.), Blanc (B.) (1975). - World Review of Nutrition and Dietetics, 20 , 66-167.

[3] ARCa (S. U. D.), Maida (B.) (1970). - Attiv. Stud. Azienda Communale Cent. Latte, Rome, 115-128.

[4] Auclair (J.) (1954). - Ind. Lait., 89, 40-42.

[5] Baumann (P.), Doudoroff (M.), Stanier (R. Y.) (1968), - J. Bact., 95, 1520-1541.

[6] Bjerre (P.), Saederup Nielsen (P.) (1978). - XXe Congr. Int. Lait., F, 817-818.

[7] BJöRck (L.) (1978). - J. Dairy Res., 45, 109-118.

[8] Bloquel (R.) (1979). - Thèse Doctorat $3^{\mathrm{e}}$ cycle, Univ, Nancy I-I.N.P.L.

[9] BockelmanN (I.) von (1966). - Milchwissenschaft, 21, 275-278.

[10] Bockelmann (I.) von (1970). - XVIII ${ }^{\mathrm{e}}$ Congr. Int. Lait., 1 F, 109.

[11] Brulé (G.), Maubois (J. L.), Vandeweghe (J.), Fauduant (J.), Goudedranche (H.) (1975). - Rev. Lait. Franç., 328, 117-122.

[12] Bundgaard (A. G.), Olsen (C. J.), Madsen (R. F.) (1972). - Dairy Ind., 37, 539-546.

[13] Chapman (H. R.), Bines (V. E.), Glover (F. A.), Skudder (P. J.) (1974). J. Soc. Dairy Techn., 27, 151.

[14] Chojnowski (W.), Poznanski (S.), Smietana (Z.), Bednarski (1978). $-X X^{\mathrm{e}}$ Congr. Int. Lait., F, 961-962.

[15] Covaceitch (H. R.), Kosikowski (F. V.) (1977). - J. Food Sci., 42, 1362-1365.

[16] Covaceitch (H. R.), Kosikowski (F. V.) (1978). - J. Dairy Sci., 61, 529-535.

[17] Covaceitch (H. R.), Kosikowski (F. V.) (1978). - J. Dairy Sci., 61, 701-709.

[18] Chaplet (C.) (1971), - Thèse Doctorat en Médecine, Paris.

[19] Davis (A. E.), Bolin (T. D.) (1967). - Nature, 216, 1244-1245.

[20] Dempster (J. F.) (1968). - J. Appl. Bact., 31, 290-301.

[21] DURr (R.) (1974), - Rev. Lait. Franç., 326, 913-919.

[22] Evans (E. W.), Glover (F. A.) (1978), - XX Congr. Int. Lait., F, 660.

[23] Foster (E. M.), Nelson (F. E.), SpeCk (M. L.), Doetsch (R. N.), Olson (J. C.) (1957). - Dairy microbiology. Prentice Hall, Inc. Englewood Cliffs, New Jersey.

[24] Garcia-Ortiz (R.) (1978). - D.E.A. Science de l'Alimentation, I.N.P.L., Nancy.

[25] Georgakis (S. A.) (1978). - XX $X^{\mathrm{e}}$ Congr, Int. Lait., F, 810-811.

[26] Gilardi (G. L.) (1975). - Health Lab. Sci., 12, 311-315.

[27] Glover (F. A.), Skudder (P. J.), Stithart (P. H.), Evans (E. W.) (1978). J. Dairy Res., 45, 291-318.

[28] Greene (V. W.), Jezeski (J. J.) (1957). - J. Dairy Sci., 40, 1053-1061.

[29] Hansen (R.) (1977). - Nordenrop. Mejeri Tidssk, 9.

[30] Hellmann (E.) (1969). - Archiv. Lebensmittel-Hyg., 20, 241-246.

[31] JaCobsen (M. K.) (1978), - XX ${ }^{\mathrm{e}}$ Congr. Int. Lait., F, 809-810.

[32] Jacouemet (J. C.) (1978), - XX Xe Congr. Int. Lait., F, 934-935. 
[33] Jaquet (J.), Thévenot (R.) (1961). - Encyclopédie du froid, J. B. Baillère, Paris.

[34] Jaquet (J.), Coiffier (O.) (1978). - Le Lait, 573-574, 111-117.

[35] JePSen (S.) (1977). - Dairy Ice Cream Field, 160, 78-82.

[36] Johns (C. K.) (1959). - J. Dairy Sci., 42, 1625-1650.

[37] Juffs (H. S.) (1974). - Aust. J. Dairy Techn., 29, 74-78.

[38] Kiuru (K.), Eklund (E.), Gyllenberg (H.), Antila (M.) (1971). - Milchwissenschaft, 26, 138-141.

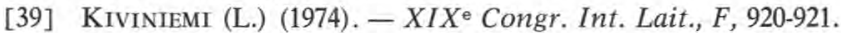

[40] Kiviniemi (L.), Seuranen (A.) (1974). - Kemia-Kemi, 1, 791-795.

[41] KNUdSEN (K. O.) (1976). - Dansk Veterinaertidsskrift, 59, 998-1016.

[42] KRETCHMER (1971). - Gastroenterology, 61, 805.

[43] Law (B. A.), Reitter (B.) (1977). - J. Dairy Res., 44, 595-599.

[44] Leitchter (J.) (1971), - Dig. Diseases, 17, 1.

[45] Mahaut (M.), Maubois (J. L.) (1978), - XX Congr. Int. Lait., F, 804.

[46] Marth (E. H.), Frazier (W. C.) (1957). - J. Milk Fd Techn., 20, $72-78$.

[47] Matthews (M. E.), So (S. E.), Amundson (C. H.), Hill Jr (C. C.) (1976). J. Food Sci., 41, 619-623.

[48] Maubois (J. L.) (1978). - XXe Congr. Int. Lait., conf. $\mathrm{n}^{\circ} 10 \mathrm{ST}$.

[49] Maubois (J. L.), Mocouot (G.) (1971). - Le Lait, 508, 495-533.

[50] Maubois (J. L.), Mocouot (G.) (1975). - J. Dairy Sci., 58, 1001-1007.

[51] Maubois (J. L.), Moceuot(G.), Vassal (L.) (1969). - Brevet français, $\mathrm{n}^{\circ} 2052$ (2).

[52] Maubois (J. L.), Kosikowski (F. V.) (1978). - J. Food. Sci., 42, 1362-1365.

[53] Maubors (J. L.), Kosikowski (F. V.) (1978). - XX e Congr. Int. Lait., F, 803-804.

[54] Maubois (J. L.), Kostkowski (F. V.) (1978). - J. Dairy Sci., 61, 881-884.

[55] Mc Kenzie (D. A.), Robinson (K.) (1962). - J. Appl. Bact., 25, V.

[56] Millière (J. B.) (1978). - Thèse Docteur-Ingénieur, Univ. Nancy I.

[57] Millière (J. B.), Veillet-Poncet (L.) (1979). — Le Lait, 581-582, 56-78.

[58] MottaR (J.), Delbeke (R.) (1978). - XX $X^{\mathrm{e}}$ Congr. Int. Lait., F, 807-808.

[59] Mourgues (R.), Auclair (J.) (1965). - Ind. Lait., 220, 192-198.

[60] Muir (D. D.), Phillips (J. D.), Dalgleish (D. G.) (1979). - J. Soc. Dairy Techn., $32,19-23$.

[61] Nakae (T.) (1968). - J. Agric. Chem. Soc. Japan, 42, 639-644.

[62] Olsen Delaney (A. G.) (1977). - Milchwissenschaft, 32, 651-653.

[63] Orr (M. Y.), Mc Larty (R. M.), Mc Cance (M. E.), Batne (S.) (1964). Dairy Ind., 29, 169-173.

[64] Panes (J. J.), Thomas (S. B.) (1959), - J. Appl. Bact., 22, 272-277.

[65] Panes (J. J.), Thomas (S. B.) (1968). - J. Appl. Bact., 31, 420-425.

[66] Pastore (M.) (1974). - Il Latte, 489-491.

[67] Pawlik (S.), Babuchowski (K.), Rembowski (W.), Skrzypek (J.), Zgiernicka (A.) (1978). $-X X^{\mathrm{e}}$ Congr. Int. Lait., F, 651-653.

[68] PerI (C.) (1974). - Il Latte, 492-495.

[69] Portmann (A.), Gate (Y.), Auclair (J.) (1962). - XVI Congr. Int. Lait, F, 729-735.

[70] Primatesta (G.) (1975). - Mondo del Latte, 29, 708-710.

[71] Рвокорек (В.), Voss (E.), Thomasow (J.) (1978). - XX e Congr. Int. Lait., F, 805-806. 


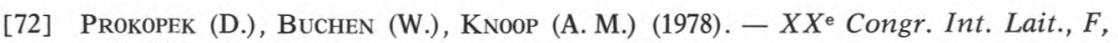
806-807.

[73] Reitter (B.) (1978). - J. Dairy Res., 45, 131-137.

[74] Rousseaux (P.), Maubois (J. L.), Mahaut (M.) (1978). - XX e Congr. Int. Lait., $F, 805$.

[75] Samagh (B. S.), Cunningham (J. D.) (1972). - J. Dairy Sci., 55, 19-24.

[76] Schultze (W. D.), Olson Jr (J. C.) (1960). — J. Dairy Sci., 43, 351-357.

[77] Serap Alvarez (D.), Bennasar (M.), Tarodo de la Fuente (B.) (1979). - Le Lait, 59, 376.

[78] Тномаs (S. B.) (1974). - J. Soc. Dairy Techn., 27, 180-188.

[79] Thomas (S. B.), Druce (R. G.) (1963). - Dairy Engng, 80, 378-381.

[80] Thomas (S. B.), Druce (R. G.) (1969). - Dairy Ind., 34, 351-355, 430-433, 501-505.

[81] Thomas (S. B.), Druce (R. G.) Elson (K.) (1960). - Dairy Ind., 25, $202-207$.

[82] Thomas (S. B.), Hobson (P. M.), Bird (E. R.) (1959). - XVe Congr. Int. Lait., 3, 1334-1340.

[83] Thomas (S. B.), Thomas (B. F.) (1975). - Dairy Ind., 40, 478-480.

[84] Toppino (P. M.), Nani (R.), Cabrini (A.) (1978). - XXe Congr. Int. Lait., F, 842-843.

[85] Vakil (J. R.), Chandan (R. C.), Parky (R. M.) Shahani (K. M.) (1969). - J. Dairy Sci., 52, 1192-1197.

[86] Veinoglou (B.), Boyatzoglou (E.), Anifantakis (E.) (1978). $-X X^{e}$ Congr. Int. Lait., $F, 808-809$.

[87] Veinoglou (B.), Anifantakis (E.), Stiakakis (J.) (1978). $-X X^{\mathrm{e}}$ Congr. Int. Lait., $F, 841$.

[88] Wasserfall (F.) (1978). - Milchwissenschaft, 33, 91-96. 